\title{
BUILDING A NUTRITIONAL PLAN TO SUPPORT PROLONGED EXERCISE
}

\author{
Fabiana MARTINESCU \\ "Romanian-German" University of Sibiu, Romania \\ fabiana.martinescu@yahoo.com
}

\begin{abstract}
Over the years, we have heard numerous discussions and views on the nutritional plans for the bodybuilding and fitness practitioner. The most controversial meal of the day is with no doubt the dinner. Supporters of the principle according to which dinner should be eliminated and the last meal of the day should be taken in the afternoon, support their theory with solid arguments, at least theoretically. The others, more tolerant, recommend that dinner is taken at least one hour before going to bed and the latter bring relevant counterarguments to support their opinion. It is no less true that what, how much and when you are eating in the evening is essential in achieving the set goals. For example, for someone interested in increasing body weight and muscle, dinner and its caloric intake is particularly important. On the opposite end are those who want to lose weight and even more, want to keep their muscle. They will definitely not try to get more calories, but will be interested in where these calories come from.
\end{abstract}

\section{Keywords: nutritional plan, bodybuilding, fitness}

\section{Introduction:}

Therefore, if you want to lose weight, the last meal should be taken around 2 hours before going to sleep. It is not recommended to feel severely hunger, but rather a slight hunger. Let's suppose you will listen to your instinct and you will eat right before going to sleep. This way, not only you will not lose weight, but chances to store fat, as a result of the fact that when we eat metabolism slowly grows, and this effect is diminished during the night, when caloric intake is reduced to the level of maintaining basic functions of the body. Consequently, the metabolic benefit that having a meal during the day might bring is turned into damage.

A meal taken right before sleep not only affects the process of losing fat during the night, but it affects the next day's metabolism. Unconsumed energy reserves will affect the entire process of the next day's meals, starting with breakfast which, in this case, might be skipped, thus depriving the athlete of its numerous benefits.

To summarize, we believe that it must be taken into account that the last meal of day is taken at least an hour before sleep and it does not include high amounts of carbohydrates, especially those with high glycemic index (pasta, potatoes, sugar), because sudden increase of insulin affects the release of growth hormone during the night.

To reduce hunger during night, it is recommended that throughout the day, small, healthy, nutritionally balanced meals are taken, at an interval of about 3 hours.

The last meal of the day should contain protein from fat free and low calories content food (baked chicken breast) and carbohydrates from fibrous plant food, to stimulate bowel transit. 
For those interested in muscle hypertrophy, a protein shake is recommended, containing casein, low absorption protein that will cause constant and long flow of amino acids in the blood and will protect the body against catabolic processes during the night. Also, having a meal with fat free dairy products (fat free cottage cheese, etc.) is a good choice.

\section{The nutritional plan:}

An optimal nutritional plan will consider reaching the set goal, take into account existing eating habits, possible medical conditions. Together with nutritional supplements, it will have to sustain the effort made at the gym, but also lead towards the desired physical shape.

Moreover, an efficient nutritional plan considers anthropometric data of the athlete, the existing level of fat and his basic metabolism.

Calculating the necessary number of calories is calculated after a scientific formula. Calories' calculation is done for the moment when the body is in total relaxation, rested, normal emotivity and the surrounding temperature is between 18-20 degrees Celsius. The basic metabolism calculation depends on: weight, size, gender, age, mental state, diet, physical activity. World Health Organization (W.H.O.) has elaborated, after studies on nutrition, several equations with which we can calculate the needed calories. In the table below, the numbers are indexes established by W.H.O. and the letters are variables of which $\mathrm{W}=$ weight and $\mathrm{H}=$ height

\begin{tabular}{|c|c|c|}
\multicolumn{3}{|c|}{ Table 1) The amount of calories/day } \\
\hline Ages & $\begin{array}{c}\text { For men (cal } \\
\text { / day) }\end{array}$ & $\begin{array}{c}\text { For women } \\
\text { (cal / day) }\end{array}$ \\
\hline $10-18$ years & $\begin{array}{c}16,6 \mathrm{~W}+ \\
77 \mathrm{H}+572\end{array}$ & $\begin{array}{c}7,4 \mathrm{~W}+482 \mathrm{H} \\
+217\end{array}$ \\
\hline $18-30$ years & $15,4 \mathrm{~W}-$ & $13,3 \mathrm{~W}+$ \\
$27 \mathrm{H}+717$ & $334 \mathrm{H}+35$ \\
\hline $30-60$ years & $11,3 \mathrm{~W}+$ & $8,7 \mathrm{~W}-25 \mathrm{H}$ \\
$16 \mathrm{H}+901$ & 865 \\
\hline Over 60 & $8,8 \mathrm{~W}+$ & $9,2 \mathrm{~W}+637 \mathrm{H}$ \\
years & $128 \mathrm{H}-1071$ & -321 \\
\hline
\end{tabular}

A correct nutritional plan includes all macro and micro-nutrients necessary to a good functioning of the body (carbohydrates, lipids, protides, vitamins and minerals). The key to any long-term nutrition program is consistency,but don't worry about this being a boring diet. [1] Either it is about bodybuilding or fitness or the approach to lose or gain weight, the idea of keeping on a diet is undoubtedly an act of will and total dedication, without which success is overdue. Of course, keeping on a diet assumes avoiding some common mistakes that, in the end, may destroy the athlete's effort. Here are some of them.

Consuming many calories when you want to increase muscles is not a good idea because sooner or later the great amount of calories will turn into fat. The main desire is to accumulate muscles and not cover the body with fat. Therefore, establishing and thoroughly complying with the number of calories needed, as well as the relations proteins/carbohydrates/fat is also a good move.

In a study of bodybuilders during the twelve weeks before competition, male competitors reduced their caloric intake significantly during the latter half and subsequently lost the greatest amount of LBM in the final three weeks. [2]. Competitive bodybuilding requires cyclical periods of weight gain and weight loss for competition [3].

Many of those who are on a diet are not patient enough, "jumping" from one diet to another, giving no chance to the initial plan. From experience, a diet requires at least one month to prove its effectiveness and for the body to get used to the new conditions, either you are interested in losing weight or gaining weight.

Another common mistake is to not have a day when you can cheat. Mentally speaking, this day is very important, because it gives resources to continue the diet. It is preferable that the meal that includes "something else" is in the morning, giving the body the possibility to burn the excess of calories during the day. 
Certainly, cheating is beneficial, but exaggerating is counterproductive.

A diet often fails when planning the entire this is badly done. The diet should be regarded as a unitary process together with a customized and efficient training programme which should not exclude cardio exercises. The diet should not be regarded as a temporary situation or as a torture that you have to accept, but as a new and healthy way of living.

A situation that generates failure is when the person who wants to lose weight does not eat enough. The body cannot distinguish between moderate reduction in calories and starvation and thus will reduce metabolic rate to fight the deficit of calories and loss of weight. To deal with this "boomerang" effect, you should increase metabolic rate through specific training programmes, establish a caloric deficit of approximately 200 calories below the level of maintenance and divide the total of calories ingested in 4-6 meals.

Keeping a diary of the types and quantities of consumed food and supplements as well as their conversion into calories, in a table with nutritional information spares the athlete from unpleasant confusion and countless blunders. With a diary, he would be able to figure out fast what mistakes he has done or what food suits him best.

It is a very good idea to keep diets found in all kinds of magazines, but rather to use them as a basic guideline, to create your own nutritional plan. The diet is an absolutely individual thing, as every individual is unique.

When you decided to start a diet, the use of alcohol should be avoided. Alcohol brings a surplus of calories that the body metabolizes rather as fat than as carbohydrates, without any benefit for muscle growth or loss of weight.

No great changes should be made all of a sudden. The body must have time to adapt. For those who want to grow muscles, a surplus of approximately 300 calories coming from quality nutrients guarantees muscle growth with minimum fat accumulation. One of the major mistakes is when the person who is on a diet does not drink enough water. Lack of water may cause hunger and lead to dehydration. Water is also responsible for body detoxification and the good functioning of its systems. A minimum of 3 litres a day is absolutely necessary.

Competitive bodybuilders are not alone in their risk and disposition towards behaviors that carry health concerns. Elite athletes in aesthetic and weight-class sports as a whole share these risks [4].

\section{Bodybuilding and fitness for vegetarians}

I have always considered a thorough and balanced diet should contain meat. I am convinced that this perception has its roots, on one hand, in my childhood, when the effort of standing in line at the meat shop gave me the feeling that there is no life without meat and, on the other hand, in the Romanian eating habits where meat, according to a study, is found in $66 \%$ of the specific cuisine.

The question is whether you can practice bodybuilding and fitness, even of performance, without eating meat.

With regard to vegetarians, it is obvious that they have not included meat or different kinds of meat in their diet. They are divided into several categories, depending on the types of food they eat, namely:

- Ovo-vegetarians - are those who eat, together with vegetables, eggs, egg products, but without consuming dairy products;

- Lacto-vegetarians - are those who eat, together with vegetables, milk and dairy products, without consuming eggs;

- Ovo-lacto-vegetarians -are those who, together with vegetables, eggs, milk and products derived therefrom, alongside with honey. This is practically the most common form of vegetarianism accepted by the society;

- Vegans - are those who have excluded from their diet any animal product (milk, eggs, honey). In this situation, things go even further, and they refuse any product 
tested on animals, as well as clothing and footwear of animal origin. Among these ones, there is particular category, namely the vegans that consume only vegetable products in raw shape (unprocessed thermally);

- Buddhist vegetarians - are those who have excluded from their diet any animal product (milk, eggs, honey) and the vegetables from "Allium" family (onion, garlic, leek, etc.).

Probably, the next discussion should be related to the reason that led to the choice made by them. In the rough, the reasons are related to religious, health and ethics aspects.

Some religions forbid the consumption of meat in certain periods of the year. For Catholics and Orthodox this period is called "fast". The same situation is met at Buddhists. In terms of excluding meat from alimentation on health grounds, there is a serious controversy, because meat is considered the cause of some heart diseases, diabetes, cancer and many others. It is considered that returning to a primary nutrition, based on vegetables, would keep up away from these health problems. Not long ago, I have watched a documentary from last year, called "Forks over knives" and which was based on a study carried out on a group of doctors from China over a period of 20 years. They tested a Western diet, based on animal products and processed food products. It was noticed that this type of nutrition is guilty of dental problems, skin diseases, loss of hair, cancer, digestive diseases, arthritis and many other complications. The interesting thing is that, according to the study, after turning back to the primary diet, health problems have improved.

Vegetarianism on ethical grounds is another explanation for those who do not eat meat. Cruel treatments inflicted on animals, almost sadistic methods used to sacrifice them and conditions which they are raised in are subject to numerous social debates. Currently, there are thousands of animal protection associations, which have as main goal public opinion awareness regarding these aspects and which fervently advocate for abstention from meat.

Beyond the vegetarians' reasons presented above, there is another question: is it healthy to be a vegetarian? At first sight, anyone may be tempted to think that depriving the body from those nutrients contained by meat will lead to incomplete nutrition and, consequently, to health problems. For example, some time ago, it was supposed that in order to obtain a high biological value protein, such as that from meat, we must combine certain categories of vegetables. Once again, scientific research has shown that this theory is false and, in addition, it has been demonstrated that most micronutrients found in meat (vitamin B12, iron, etc.) have correspondents in vegetable products, milk and eggs.

The hypothesis that vegetarians can take from food enough proteins is supported by comparisons between nutritional values of vegetable products and meat. To support this idea, arguments such as the destructive effect of thermal treatment on the biological value of protein from meat are presented.

Besides lab studies, the fact that over the years athletes in bodybuilding and fitness such as Bill Pearl, Albert Beckles and Reachelle Chase have demonstrated that performance can be reached being a vegetarian, confirms that a healthy nutrition can exclude meat.

As far as I am concerned, I believe that the truth, as always, is somewhere in the middle. Of course, credit should be given to those who chose vegetarianism, but there should not be blamed those who still eat meat. The word that should dominate each of our existence is moderation; the same should happen when we are talking about nutrition.

Types of diets depending on the set goal If we were to think about prehistoric man for a second and try to imagine ourselves how he managed to get his food, either as a hunter, harvester or fisherman, we should feel lucky to be the happy owners of $21^{\text {st }}$ century civilization's comfort. It is a huge 
difference between the effort and adrenaline of bringing down a buffalo with a spear and the peace and quiet of pulling a cart in the supermarket, but the end of both actions is the same: getting food. The dangers existed then, but they exist now, too. If for the prehistoric man, once he carried his capture to the cave his only danger was the danger of indigestion, for the man today, the dangers occur only after he finished arranging the "capture" he has just bought into the fridge.

Here are some basic elements that should be considered when buying food. The first step would be that the athlete sets his goals regarding body weight, namely whether he wants to increase weight or to lose weight. In both situations, for an athlete or for someone to whom his/her own image matters, nutrition is essential. Therefore, choosing the proper food items to achieve the set goals could be a matter on which the success of a diet depends. Another step would be to establish with precision a shopping list that we respect and that we do not deviate from, since it is well known that a product already bought is much harder to be avoided and the tendency to consume it is much higher than when it is not in our fridge. Undoubtedly, the shopping list assumes creativity, especially when we buy food for a longer period of time, a few days or a week; monotony in nutrition is one of the causes leading to failure of nutritional programmes. The shopping list should be in accordance with the set diet. Moreover, if the shopping list was drawn up rigorously, it will reduce your time allocated to shopping, relieving you from the unpleasant "fumble" through the shelves with the unbearable question on the mouth "what else could I buy?"

\section{Conclusions:}

An important aspect is to read the nutritional information on each product that we put in our shopping bag. Each of us should be aware that the main interest of food producers is to sell their products and thus, they will use a number of tricks that, in the end, will lead to the set goal. Far from me to make a process of intent, but if we were to consider only what is written on the front side of the label of a product, we would see that $90 \%$ of what is on the shelves brings health and possibly eternal youth. The facts are different: there are numerous products that display " $2 \%$ fat" written violently big and when nutritional information is read,it can be noticed that the product contains 30\% sugar. For someone who intends to lose weight, this is definitely a disaster. Also, when we read the table with nutritional information of a certain product, we must take into account that some producers show nutritional values per portion and not per 100 grams of product. We should also know that details on "reference daily intake - RDI"are established for people whose needs are average, those of a hard working athlete being much higher.

The number of calories is also very important, but it is more importantwhere they come from. Special attention should be given to the biological value of a product's nutrients: for example, not all proteins are equally valuable - carbohydrates are either simple or complex, and fat are saturated, poly-saturated or mono-saturated. Therefore, the impact each of them has on the body is different. Side substances that can be found in processed food, preservatives, flavours, sweeteners, salt, etc. should be considered when choosing a product. I do not believe there is anyone who has not heard of the bad effects of the "E numbers" on our health and therefore, it is desired to choose food in a form as natural as possible.

I believe that everyone should learn to choose their food cleverly and be very exigent when buying food. 


\section{REFERENCES:}

1. Gerard Dente with Kevin J. Hopkins, Macrobolic Nutrition, Priming Your Body To Build Muscle \& Burn Fat, Basic Health Publications, Inc., (USA, 2004)8

2. Newton LE, Hunter GR, Bammon M, Roney RK: Changes in psychological state and selfreported diet during various phases of training in competitive bodybuilders. (J Strength Cond Res 1993) 7:153-158,

3. Helms et al.: Evidence-based recommendations for natural bodybuilding contest preparation: nutrition and supplementation. (Journal of the International Society of Sports Nutrition 2014), 14

4. Sundgot-Borgen J, Garthe I: Elite athletes in aesthetic and Olympic weight-class sports and the challenge of body weight and body compositions. (J Sports Sci 2011, 29 (Suppl 1)), 101-114

\section{BIBLIOGRAPHY:}

1. Avramescu T, Curs nutriție și doping, Craiova, 2010 [online]: http://cis01.central.ucv.ro/educatie_fizicakineto/suportcurs/master/nutritie_doping/Nutritie doping_curs.pdf

2. Damian S. Nutritia in baschet si in alte sporturi de echipa, 2011 [online]: http://nutritionist.info.ro/2011/09/29/nutritia-in-baschet-si-alte-sporturi-de-echipa/.

3. Dragan I. Medicina sportive aplicata, Bucuresti, Edit.Editis, 1994.

4. Haff, G.G."Roundtable Discussion: Low Carbohydrate Diets and Anaerobic Athletes." Strength and Conditioning Journal 23, no. 3 (2001)

5. Hâncu N, Niţă C, Crăciun A. Abecedar de nutriţie. Sănătate Press Group, Bucureşti, 2012

6. Spagnoli F; Sportul incepe intodeauna la masa, Revista Sport si Sanatate, iulie 2004, Talbott S.M, A Guide to Understand Dietary Supplements, Binghampton, NY, Haworth Press 2003. 